\title{
TYPE I DIABETIC YOUTH: IS THE NEW ZEALAND HEALTHCARE SYSTEM FAILING THEM?
}

Ella $\mathrm{Ng}$

\section{INTRODUCTION}

The youth are our future, yet there is concern that the Ministry of Health and the New Zealand healthcare system is not doing enough to help our youth living with Type I Diabetes, particularly in regard to the transition process from paediatric to adult services. Not only is New Zealand's healthcare system facing an increase in the number of people living with Type I Diabetes, this health issue could potentially be contributing to an increase in acute hospital admissions, more pressure on long-term patient services and a substantial gap in meeting the needs of people living with Type I Diabetes (American Diabetes Association, 2007). This review has been developed in the hope that the Ministry of Health will work in collaboration with district health boards, to provide a structure or a plan that is suited to the needs of youth living with Type I Diabetes during their transition process, with the goal of improving their health outcomes.

\section{BACKGROUND}

There is evidence that youth living with Type I Diabetes struggle with managing the fluctuation of their haemoglobin Alc levels (HbAIc) (Castle et al., 2017; Levy-Shraga et al., 2016). International research has shown that transitioning youth to adult services can negatively impact the young person's health condition management and overall wellbeing (American Diabetes Association, 2007; Sheehan, Coyne \& While, 2014; Garvey, Markowitz \& Laffel, 20I2; Pyatak et al., 20I4). Our community has a responsibility to deliver health care services based on current knowledge of best practice. The growing awareness of the specific needs of youth living with Type I Diabetes has highlighted that New Zealand needs to explore the findings from international research in regard to improving service delivery and healthcare pathways for our youth.

\section{DISCUSSION}

There are 250,000 New Zealanders currently living with Type I Diabetes (Ministry of Health, 20I6), with one in 5000 people under the age of 15 years with this condition (Southern Cross, 2019). Diabetes is prevalent across the life span; the age of people living with Type I Diabetes can range from neonatal to the elderly. Blood glucose monitoring is part of the standard of care for people living with Type I Diabetes. Blood glucose control determines the health of the individual and predicted health outcomes. Higher blood glucose levels are associated with an increase in HbAlc levels. Higher HbAlc levels can increase risks of diabetes-related complications such as, cardiovascular disease, retinopathy, neuropathy, and renal impairment (Sapra \& Bhandari, 2020). Currently, New Zealand's standard care for people living with Type I Diabetes is divided between specialist paediatric and adult services, with transitioning between these services occurring between 15 to 18 years (Starship, 2020). 
A study conducted by Castle et al, (2017), assessed HbAlc levels of children and young people living with diabetes in the Otago region, aged from 0 to 18 years. The average $\mathrm{HbAIC}$ level for children aged between 0 to 12 years was $71-75 \mathrm{mmol} / \mathrm{L}$, whereas children aged from 13 to 18 years ranged from $77-84 \mathrm{mmol} / \mathrm{L}$. The study found that only one in 38 youth were meeting the HbAlc target criteria as set by the New Zealand Ministry of Health 2009 (Castle et al., 2017). The recorded increases of HbAlc levels in the $12-18$ age group may be linked to the way in which the transitioning process affects youth living with Type I Diabetes, however the impacts of transitioning between paediatric and adult services was not explicitly explored in this study.

With such a wide range of age groups, treating people living with Type I Diabetes can have many repercussions as will be discussed further in this article. The New Zealand healthcare system is potentially faced with a gap in meeting patient needs by only providing services for two age categories of people living with Type I Diabetes (Weissberg-Benchell et al., 2007).

\section{ISSUES IDENTIFIED WITH TRANSITIONING BETWEEN SERVICES}

There is a growing body of research internationally that is exploring the impacts on youth as they transition from paediatric to adult specialist services for the treatment and management of their Type I Diabetes. lyengar, Thomas and Soleimanpour (2019) found that across the different age groups of people living with Type I Diabetes, it is youth that have the worst glycaemic control overall. Not only are their HbAlc levels affected, but they also reported that there are psychological impacts as a result of transitioning between paediatric and adult services, which appear to further contribute to higher and/or more unstable HbAlc levels. Nineteen percent of youth in this study also associated the development of their depressive disorders with their diabetes (lyengar, Thomas \& Soleimanpour, 2019).

Wessiberg-Benchell, Wolpert and Anderson, (2007) reported that a lack of psychosocial maturity impacts on young people being able to transfer to adult services successfully. Youth are experiencing the hormonal changes linked with puberty which not only impact on physical development, but also on cognitive development, behaviour, and the individuating process. This is also supported by the findings of Sheehan, Coyne, and While (20I4), who found that transitioning from paediatric to adult services can be associated with a decrease in clinical attendance, which further results in higher HbAlc levels. According to Hockenberry et al, (2019), children with chronic illnesses face many challenges their peers do not, such as having to deal with rigorous treatment plans and being able to develop autonomy and self-efficacy.

Pytak et al, (20/4), identified that limited information about transitioning between paediatric and adult specialist services led to reduced levels of client satisfaction and a deterioration in overall HbAlc levels for youth. They researched how the organisation of the United Kingdom healthcare system left youth living with Type I Diabetes unprepared and uneducated for transition. Within a year of transitioning, the majority of the participants in the survey had a higher HbAlc level and an increase in hospital admissions related to Type I Diabetes (Pytak et al., 2014).

Zhou, Roberts, Dhaliwal and Della, (2016) found that youth who were in the process of transitioning between services voiced concerns around facing the unknown, potential communication issues, building new relationships with staff, and becoming autonomous. Coyne et al, (2014), also reported that there was little effort in engaging with the youth once they had transitioned to adult services. If there was a lapse in appointment attendance, it was considered the young person's responsibility to follow up with this, rather than the services being active in attempting to re-engage with the young person. There was evidence that suggested that the slower the transition, and the more informed the patient is regarding this process, the more responsive the young person is to engage with adult services (Coyne et al., 2019). 
It is understandable when youth with long-term chronic conditions struggle when transitioning with such a drastic change occurring in at pivotal life stage. Youth living with Type I Diabetes often feel like they do not have a collaborative healthcare team working for them. Often this mistrust leads to non-attendance to clinical appointments, which can contribute to a deterioration in health (Garvey et al., 20I2). It is important for health professionals to assist young adults with Type I Diabetes to achieve good health outcomes, by acknowledging the emotional, social and cognitive factors that can impact during transitioning periods (Rasmussen, Ward, Jenkins, King, \& Dunning, 20II). Wessiberg-Benchell et al, (2017), identified that there is a substantial gap between a paediatric outpatient clinic environment and adult clinics, and that services did not provide enough support during the time of transitioning. They found that both adult and paediatric services lack resources that are relevant to youth living with Type I Diabetes (Wessiberg-Benchell et al., 2017).

The key themes that emerge from the exploration of the international literature are:

- youth living with Type I Diabetes have an increased risk of experiencing increases in their HbAlc levels during the transition between paediatric and adult specialist services and that this is linked to an increase in acute hospitalisations and other health consequences,

- that young people report feeling poorly prepared for the transition process and unsupported once they have transitioned to adult services, and this appears to impact on clinic attendance rates,

- that both paediatric services and adult services do not have resources appropriates to the specific needs of youth living with Type I Diabetes.

With such a vulnerable group, it is likely their needs are not being met by only having two disciplinary teams working with New Zealand youth living with Type I Diabetes.

\section{A NEW APPROACH}

Changes in services affect the way in which youth are supported in managing their Type I Diabetes; there is a need for a multifaceted service that more closely correlates with the challenges that a young person may be facing. Levy-Sharga et al, (2015) found that the process of transitioning with a tailored approach can contribute to an improvement in HbAlc levels. A dedicated transition clinic was opened for 53 type I diabetics to assess if HbAlc levels improved under a tailored service for adolescents. The study showed that this specific service appeared to lead to an improvement in $\mathrm{HbAlc}$ levels by 10 percent The transition included specific resources and care for adolescents with Type I Diabetes; which led to an improvement in clinic attendance and overall health outcomes for the young people involved. The study concluded that a tailored approach to services, resulted in a successful transition for youth living with Type I Diabetes (Levy-Sharga et al., 2015).

\section{RECOMMENDATIONS}

The first and most crucial recommendation is for there to be New Zealand based research around the transitioning process of youth living with Type I Diabetes. While there are various studies around the globe, there are currently none related to the New Zealand specific health context. With 250,000 people living with Type I Diabetes, it is one of the most significant health issues New Zealand is facing (Ministry of Health, 2019), but there is no current New Zealand specific research on the impacts of transitioning youth living with Type I Diabetes from paediatric to adult services, and most importantly on how this process impacts on their HbAlc levels.

By working collaboratively, the Ministry of Health, district health boards, and health education providers could conduct research related to the transition process. This could provide information that is relevant to New Zealand's population and enable the Ministry of Health and district health boards to take action as needed. With 
such a such a potentially significant gap in the health care system, it is important that further studies measure young people's experiences and health outcomes. This will provide better information around successful transitioning, as recommended by Hodnekvam, Iversen, Brunborg and Skrivarhaug (2020).

Secondly, I would suggest creating a framework for transitioning care relevant to the New Zealand context. Various studies have highlighted that when the process of transitioning is more structured, compliance with monitoring blood glucose levels, taking medication, clinic attendance, and client satisfaction increase. Currently there are no services specifically tailored to youth living with Type I Diabetes available in New Zealand. By creating a framework, that is developed collaboratively with young people and their family/whānau, youth living with Type I Diabetes will feel more involved, better understood and will ideally be more engaged in their care. With this implemented there is hope that it would contribute to improved overall health outcomes for youth living with Type I Diabetes in New Zealand.

\section{CONCLUSION}

Having identified the challenges youth living with Type I Diabetes face when transition from paediatric to adult services, what we see is a need for a multifaceted approach to the service. As discussed earlier, international research has highlighted the gap between paediatric and adult settings, that both types of service lack specific resources that are needed to support youth living with Type I Diabetes, and the negative impacts this can have on their health outcomes.

Although there is significant international evidence which supports the tailored approach to the transitioning of services, there is no current New Zealand specific research. It is recommended that this research is done to gain better insight and understanding of how the transition process affect youth living with Type I Diabetes, and the benefits of having a specific services tailored to this group. The Ministry of Health needs to work collaboratively with the district health boards and health care education providers to support this research. If this research is in line with international findings, then the Ministry of Health and district health boards need to work collaboratively with their communities to develop services that truly meet the needs of youth living with Type I Diabetes in our country.

\section{ACKNOWLEDGMENTS}

I would personally like to thank my Mum, Paula and my Dad, Wing-wah for supporting me in my journey through living my life with Type I Diabetes. There have been many trials and tribulations that I have faced, and I know you have been with me every step of the way. I would also like to thank my diabetic paediatric team for supporting and helping me through all my years of growing. I would especially like to thank Dr. Tomlinson for guiding me in the right direction, the constant support and providing me with the best care. A big thank you to Catherine May for helping me edit this work and guiding me in the next advancement into becoming a professional.

Ella $\mathrm{Ng}$ is a student currently in her final year of study towards a bachelor's degree in nursing. Ella has had a longterm involvement in diabetes, since being diagnosed at the age of two years, her passion for helping children with long-term chronic condition resonates through this work. Ella is hoping to continue influencing and changing the way diabetes is viewed within New Zealand upon graduation.

Correspondence to Ella Ng, Otago Polytechnic Dunedin, New Zealand. Email: ellalynne.ng@gmail.com 


\section{REFERENCES}

American Diabetes Association. (2007). Transitioning from paediatric to adult care: A new approach to the post-adolescence young person with Type I Diabetes. Diabetes Care, 30(10), 244I-2446. https://doi.org/I0.2337/dc07-1249

Castle, C., Alsweller, A., Crawford, W., Drinkwater, B., Cederman, T., Kersey, E., ... Gaston, M. (2017). Glycaemic control in Otago children with Type I Diabetes. New Zealand Medical Student Journal 25, 29-32. Retrieved from http://www.nzmsj.com/ uploads/3/I/8/4/31845897/29_issue_25issue_25_webcopy.pdf

Sheehan, A., Coyne, I., \& While, A. E. (2014). The experience and impact of transition from child to adult healthcare services for young people with Type I Diabetes: A systematic review. Diabetic Medicine, 32(4), 440-458. https://doi.org/I0.1 I I I/dme. 12639

Coyne, I., Sheehan, A., Henry, E., \& While, A. E. (2019). Healthcare transition for adolescents and young adults with long-term conditions: Qualitative study of patients, parents and healthcare professionals' experiences. Journal of Clinical Nursing, 28(2122), 4062-4076. https://doi.org/I0.1 III/jocn. 15006

Ministry of Health. (2019). Diabetes. Retrieved from https://www.health.govt.nz/your-health/conditions-and-treatments/diseasesand-illnesses/diabetes

Garvey, K. C., Markowitz, J. T., \& Laffel, L. M. B. (2012). Transition to adult care for youth with Type I Diabetes. Current Diabetes Report, 12, 533-54I. Retrieved from https://doi.org/I0.1007/s II892-012-031I-6

Hockenberry, Marilyn J., Rodgers, Cheryl C., \& Wilson, David. (2020). Wong's essentials of paediatric nursing (I lth ed.). Amsterdam: Elsevier.

lyengar, J., Thomas, I. H., \& Soleimanpour, S. A. (2019). Transition from paediatric to adult care in emerging adults with Type I Diabetes: A blueprint for effective receivership. Clinical Diabetes and Endocrinology, 5, 3. https://doi.org//0.1/86/s40842019-0078-7

Levy-Shraga, Y., Elisha, N., Ben-Ami, M., Bokyo, V., Lerner-Geva, L., Ziv, T., ... Pinhas-Hamel, O. (2016). Glycemic control and clinic attendance of emerging adults with Type I Diabetes at a transition care clinic. Acta Diabetologica 53, 27-33. https:// doi.org/10.1007/s00592-015-0734-z

Pyatak, E., Sequeira, P., Whittemore, R., Vigen, C., Peters, A., \& Weignberg, M. (2014). Challenges contributing to disruptive transition from paediatric to adult diabetes care in young adults with Type I Diabetes. Diabetic Medicine, 3/(I2), 1615-1624. https://doi.org/10.1 III/dme.12485

Rasmussen, B., Ward, G., Jenkins, A., King, S., \& Dunning, T. (201I). Young adults' management of Type I Diabetes during life transitions. Journal of Clinical Nursing. https://doi.org/I0.1 III/j.I365-2702.2010.03657.x

Sapra, A, \& Bhandari, P. (2020). Diabetes Mellitus. Retrieved from: https://www.ncbi.nlm.nih.gov/books/NBK55I50I/

Starship. (2019). Managing diabetes in children and young people (for families). Retrieved from https://www.starship.org.nz/diabetesresources/

Weissberg-Benchell, J., Wolpert, H., \& Anderson, B. J. (2007). Transitioning from paediatric to adult care: A new approach to the post-adolescent young person with Type I Diabetes. Diabetes Care, 30(I0), 244I-2446. Retrieved from https://care. diabetesjournals.org/content/30//0/244I

Zhou, H., Roberts, P., Dhaliwal, S., \& Della, P. (2016). Transitioning adolescent and young adults with chronic disease and/or disabilities from paediatric to adult care services - An integrative review. Journal of Clinical Nursing, 25(21-22), 3113-3130. https://doi.org//0.1 I II/jocn.13326 